\title{
Zaheer-Ud-Din Babar (ed): Pharmaceutical Prices in the 21st Century
}

\author{
Springer International Publishing Switzerland 2015
}

\section{Suzanne Rose Hill ${ }^{1}$}

Published online: 21 December 2015

(c) Springer International Publishing Switzerland 2015

\section{Introduction}

This book is a collection of national case studies about pharmaceutical pricing policy. Given the current global concerns about this topic, it is a very useful addition to available data as it provides 20 different case studies from countries and regions with widely different health systems and incomes. Each chapter has been written by a local expert, in combination, in some cases, with an international author. There are two final chapters that provide a perspective on innovation, prices and the pharmaceutical industry, as well as a brief summary of pharmaceutical policies in general.

\section{What Does it Tell Us?}

Each country chapter outlines their current approach to managing pharmaceutical prices. There is contextual information about the health system, as well as the pharmaceutical sector. Some chapters provide a wealth of technical detail; for example, the section on how maximum allowable prices are managed in South Korea. This type of information is likely to be of interest to other pharmaceutical sector managers who are trying to develop similar policies. Most chapters also provide an assessment of

Suzanne Rose Hill suzannerhill@gmail.com

1 University of Melbourne Medical School, Melbourne, Australia access to medicines, although, not surprisingly, few data on this important issue are presented because data are generally sparse. The chapter about New Zealand goes further than many others in trying to link the various activities and policies implemented by PHARMAC to impact on access to medicines.

\section{What Are its Strengths?}

For many countries trying to move towards universal health coverage, managing pharmaceutical expenditures is key to planning and delivering on expanded coverage. Therefore, this book offers a wealth of examples to consider, especially for low- and middle-income countries that are in the process of changing or establishing health insurance programs. Having a consolidated reference source, such as this book, for academics interested in the field of policy analysis will obviously be very useful.

\section{What Are the Limitations?}

I went looking for a few things that I did not find. First of all, when countries are developing new systems for managing pharmaceuticals, they often want to know how to build a system, and the current 'snapshot' descriptions in most of these chapters do not provide enough guidance on how to go from where you are in system development to where you want to be. Similarly, it is incredibly useful to know what does not work-and why - and what challenges to expect. Joel Lexchin's chapter on the use of compulsory 
licensing in Canada until the 1990s provides a fascinating two-paragraph snippet about this very controversial policy that was dropped after (political?) pressure from the US and free-trade agreements; it would be wonderful to have more detail about this (although I guess I can instead go and read Joel's papers that he cites!).

Finally, I really wanted a discussion about why we are all spending time, effort and money (large sums of it in some cases) on implementing all of these policies rather than talking carefully to the manufacturers about changing pricing strategies altogether; neither chapter 21 nor 22 go near to this admittedly very hot topic. Perhaps the next book on pricing might just do that $\ldots$ because that is what we all need to understand to ensure affordable access to medicines. 